\title{
An ISO 9126 Based Quality Model for the e-Learning Systems
}

\author{
Rachida Djouab and Moncef Bari
}

\begin{abstract}
The emergence of the information and communication technology (ICT) in academia environment has contributed to the development of the e-learning systems. They have received a considerable attention in education and provided significant advantages such as convenience, flexibility and global learning community. While e-learning systems are growing significantly, there is a pressure on educational institutions and organizations to ensure the quality of e-learning systems. ISO 9126 is the most recognized and applied quality standard to specify and evaluate attributes of the software product. In this paper, ISO 9126 is extended with the specific characteristics of the e-learning software product. This extension is done by defining the quality characteristics of the e-learning system and integrating them in the ISO 9126 model. Results of this study will serve as a basis for the evaluation of an existing system.
\end{abstract}

Index Terms-E-learning, ISO 9126, software quality model, quality characteristics, online education, high education.

\section{INTRODUCTION}

The e-learning is becoming essential for many real-world tasks. It is defined as: "A learning method that uses ICTs to support teaching and learning process ubiquitously and facilitate the acquisition and use of knowledge" [1]. The exponential growth of Information and Communication Technology (ICT) has changed the education systems and contributed to the improvement of the learning process. The e-learning has reached a wider target audience of learners [2] who are 1) geographically dispersed with limited time and/or resources to travel; 2) busy with work or family commitments; 3) located in conflict and post-conflict areas and restricted in their mobility; 4) facing difficulties with real-time communication (e.g. foreign language learners).

Several learning methods have been described in literature to deliver new learning experiences [1]. They include traditional learning, e-learning, blended learning, mobile learning, and personalized learning based on learners' needs and using simulation and games. It has been revealed that the e-learning has a positive effect on students' performance and teachers' productivity [3], [4] and more learners are adopting the online learning and are more comfortable with this learning concept. A study conducted in 2008 by the U.S Department of Education, shows that during the 2006-2007 academic year, about $66 \%$ of postsecondary public and private schools were participating in student financial aid programs related to distance learning courses. $77 \%$ of enrollment for-credit courses were dedicated to the online

Manuscript received July 29, 2014; revised November 28, 2014.

Rachida Djouab and Moncef Bari are with the Department of Didactics Université du Québec à Montréal Montreal, Canada (e-mail: djouab.rachida@uqam.ca,bari.moncef@uqam.ca). component [5].

In addition, several countries have encouraged the development of e-learning systems and made more pressure on educational institutions for more flexible and efficient learning. As stated in [2], the e-learning is "good" if it provides the right people with the right skills at a reasonable cost in a timely manner. Many organizations are applying different approaches and models to evaluate their learning process. Yet, there has been considerable criticism of the quality of the systems currently being used and a lack of an effective e-learning evaluation quality model [6]-[10].

In 2004, the European survey has been conducted to analyze the quality in e-learning in general, the use/implementation of quality instruments in e-learning, and the experience with quality instruments and approaches. The study has shown that quality plays a key role in the success of e-learning, the quality development must become a core process for educational organizations and the open quality standards must be widely implemented [11].

Attention in this paper is given to quality aspect of the e-learning systems and the objective of this paper is to investigate the main factors contributing to the design of the quality model of the e-learning systems. The quality model ISO 9126 is proposed as a framework for evaluating the e-learning systems. The model is customized in accordance with specific attributes of these systems. The customization is done by extracting the quality characteristics of the web and e-learning systems and adding them to the model.

The paper is structured as follows: Section II describes the ISO 9126 quality standard and its strengths and weaknesses. A first extension of the ISO 9126n model with quality characteristics of the software product is proposed. Section III describes the characteristics of the web and e-learning systems. Section IV presents our quality approach including a second extension of the quality model with e-learning quality characteristics. Finally, the last section concludes the research study.

\section{Why ISO 9126 HAS BEEN CHOSEN TO EVALUATE THE E-LEARNING SYSTEMS}

\section{A. A Brief History on Quality Models}

The quality model is a mean to specify and evaluate the quality specifications of software. In 1977, Jim McCall [12] presented the first quality model toward the system developers and the system development process. McCall attempts to establish a link between users and developers by defining a number of software quality factors that reflect both the users' views and the developers' priorities.

The second quality model has been presented by Barry $\mathrm{W}$. Boehm [13]. Boehm's model attempts to qualitatively define 
software quality by a given set of attributes and metrics. Boehm's model presents a hierarchical quality model structured around high-level characteristics, intermediate level characteristics, and primitive characteristics.

The more recent quality model has been presented by $\mathrm{R}$. Geoff Dromey [14] and is based on the relationship between quality attributes and sub-attributes, as well as the connexion between the product properties and the software quality attributes.

\section{B. Definition of ISO 9126}

The standard ISO/IEC 9126 [15] developed by ISO/IEC JTC1 SC7 (Subcommittee SC7 - Software and Systems Engineering of International Organization for Standardization) is divided into four parts:

1) ISO/IEC 9126-1: Information technology - Software quality characteristics and metrics - Part 1: Quality model. This part provides the recommended quality model containing important quality characteristics for the final product. Quality sub characteristics and attributes refine the quality model and can be internal or external quality attributes.

2) ISO/IEC 9126-2: Information technology - Software quality characteristics and metrics - Part 2: External metrics (Fig. 1). This part provides external quality metrics for measuring software quality characteristics applicable to an executable software product during testing or operating at a later stage of development and after entering the operation process.

3) ISO/IEC 9126-3: Information technology - Software quality characteristics and metrics - Part 3: Internal metrics (Fig. 1). This part provides internal quality metrics for measuring software quality characteristics applicable to a non-executable software product during designing and coding at an early stage of the development process.

4) ISO/IEC 9126-4: Information technology - Software quality characteristics and metrics - Part 4: Quality in use metrics (Fig. 2). This part provides quality in use metrics for measuring software quality characteristics applicable to an executable software product after entering the operation process.

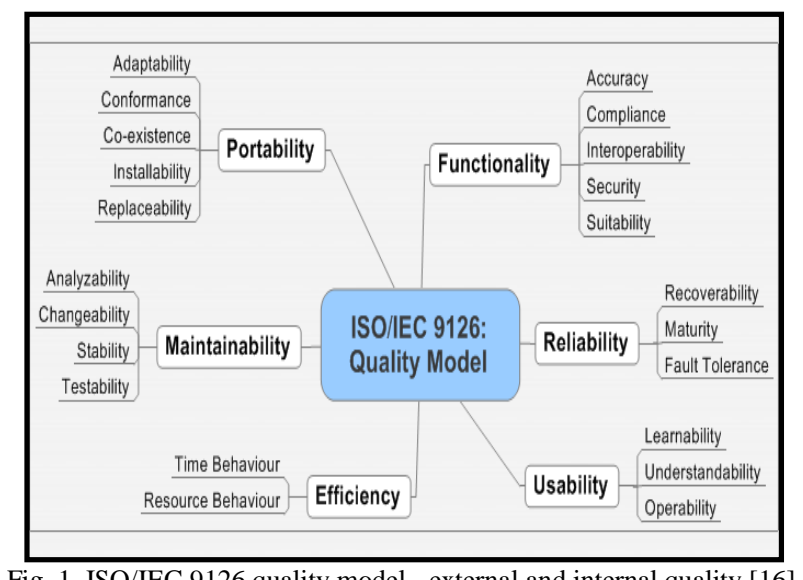

Fig. 1. ISO/IEC 9126 quality model - external and internal quality [16].

The ISO 9126 quality model was proposed as an international standard for software quality measurement in 1992. It is a derivation of the McCall model [13]. It is the most common used quality standard model. There are several others though, such as IEEE 1061. It has three levels of quality characteristics, sub- characteristics, and attributes. ISO 9126 defines 21 attributes that a quality software product must exhibit (Fig. 1). The 21 attributes are arranged in six areas: functionality, reliability, usability, efficiency, maintainability and portability. Finally, ISO 9126 identifies three models of software product quality (internal quality, external quality and quality in use). Table I presents the main advantages and limitations of the ISO 9126 quality model.

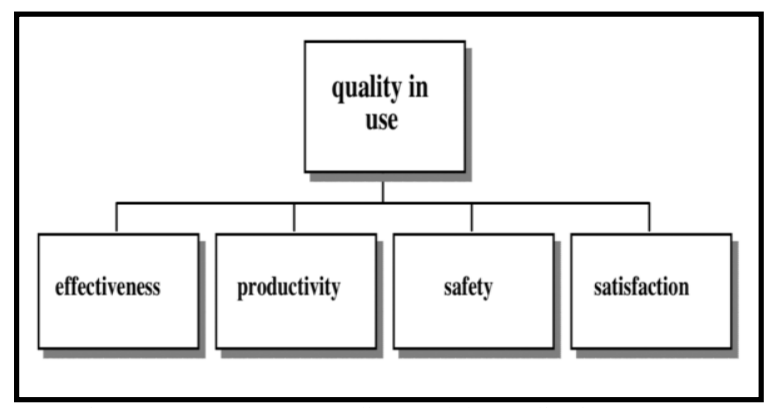

Fig. 2. ISO/IEC 9126 quality model - quality in use [17].

TABLE I: ISO/IEC 9126 MODEL ADVANTAGES AND LIMITATIONS ISO/IEC 9126 quality model

ISO/IEC 9126 is a model of quality characteristics of the software used to: discuss, plan and evaluate the quality of software products. It includes measures to measure the degree of each quality attribute of the product that can be achieved.

Major advantages:

- Unify and quantify different views of quality requirements;

- Having a single universal model makes it easier to compare one product with another.

- The characteristics defined are applicable to any kind of software while providing consistent terminology for software product quality.

- ISO 9126 covers all crucial characteristics such as hierarchical structure; criteria for evaluation; comprehensive expression and terms; simple and accurate definitions; and one to many relationships between various layers of model [18].

- ISO 9126 supports strategic decision-making activities, avoiding costly mistakes [18].

Major limitations of ISO 9126:

- One of the most important limitations of the ISO 9126 model is its generality;

- The model does not describe the business manager needs which are represented in the Return on Investment and Sustainability quality factors

- The traceability of the software and the consistence of the data are not represented in the model

- The model does not include measurements methods

Usable in the following steps:

- Definition and specification of the quality requirements of the software product;

- Evaluation of the software specification vis-à-vis the quality requirement;

- Description of traits and attributes of software implemented;

- Evaluation of software developed before delivery;

Evaluation of software developed before acceptance.

From the listed limitations, it is possible to add new quality characteristics to the ISO 9126 quality model of Fig. 1 for the software product. Fig. 3 shows the extension of the ISO 9126 model describing the common characteristics that contribute in the satisfaction of the user's needs that can be:

- The end user: for whom the usability is the most important quality characteristic;

- The software developer for whom the reliability and 
functionality are the most representative quality characteristics of the software;

- The business manager: for whom the Return on Investment and the sustainability are the main quality factors.

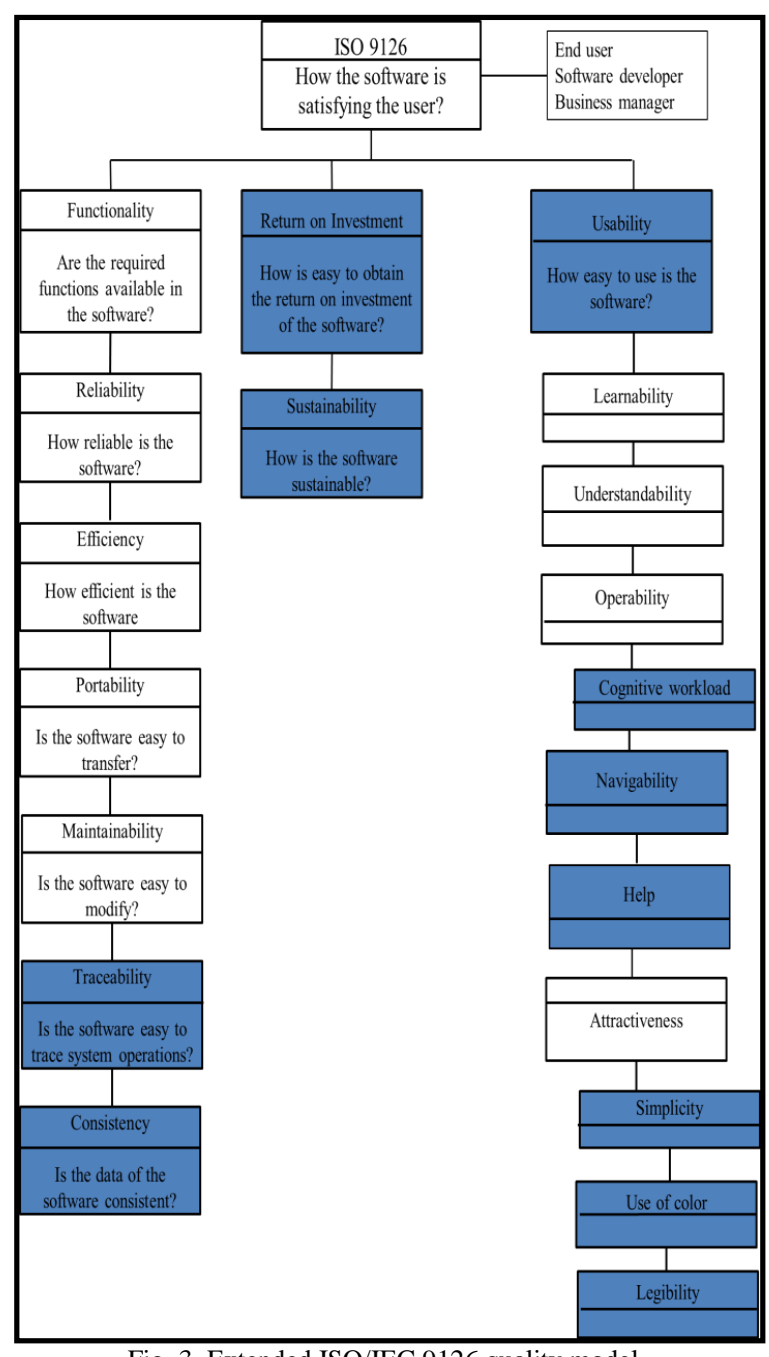

Fig. 3. Extended ISO/IEC 9126 quality model.

The proposed quality characteristics for the software product are included at the three levels of the quality model:

\section{1) Characteristics added in the first level}

1) Traceability: It is used for tracing the operations of the software [19]

2) Consistency (Data): is the data of the software consistent? [20]

3) Return on Investment: the indicator of return on investment is of the considerable concern for the business manager [21]

4) Sustainability: It refers to the extent to which the software is sustainable for the business managers [22].

\section{2) Characteristics added in the second level}

1) Navigability [19]: This characteristic refers to the ease of users' quick and efficient access to the content

2) Help under the Usability characteristic as suggested by Chua et al. [23]

\section{3) Characteristics added in the third level}

1) Cognitive workload under the sub quality characteristic Operability [24]

2) Simplicity, use of color, Legibility under the sub characteristic Attractiveness as suggested by Chua [23].

In addition, ISO 9126 has been compared with other quality models (MaCall, FURP and Dromey) [18]. The main strength of this model is that it can be used across many systems including the academic domain i.e. e-learning systems. ISO 9126 has been used to evaluate the e-learning systems for teachers and educational administrators [23], to select generic external systems quality characteristics and sub characteristics for user evaluation of course management system (CMS) (Course management systems [25]), to evaluate Computer-Based Systems [26], to analyze technological, managerial and economic factors in e-learning systems [27] and has been customized to identify acceptance criteria to evaluate a B2B application [4].

It can be concluded that the ISO 9126 is suitable to be used in the evaluation of e-learning because it is widely used in the software engineering community and has been adapted to different domains and contexts [28] and is easy to use and understand by its users. The next section presents the quality approach based on the customization of the ISO quality model to the e-learning systems.

\section{OUR QUALITY APPROACH}

Educational organizations need a good quality of the e-Learning applications to achieve the success in the exponential growing of these systems. The proposed quality approach is organized in two steps: a) define the characteristics of the e-learning systems; and b) add these characteristics to the quality model of Fig. 3.

\section{A. Define the Characteristics of the e-Learning Systems}

The generality of the ISO 9126 means that a further analysis and mapping of characteristics is required before it can be fully adapted to e-learning. From the definitions of the term e-learning [29], [1]: "Learning facilitated by internet and www technologies, delivered via end-user computing that creates connectivity between people and information and creates opportunities for social learning approaches" and [30], [1] "The acquisition and use of knowledge which is distributed and facilitated primarily by electronic means. Such electronic means may include internet, intranet, extranet, CD-ROM, video tape, DVD, TV, and personal organizers", it is clear that the quality of the e-learning systems is closely dependent of:

1) The quality of the web technologies;

2) The quality of the learning content and the used pedagogical and cognitive approaches; and

3) The Return on Investment and Sustainability of the e-learning software (business quality characteristics)

They will be detailed in turn in the next subsections.

\section{B. The Quality of the Web Technologies}

Behkamal and al summarized in their research study the quality characteristics of the web applications (Table II) and identified four quality characteristics of the B2B applications [19]: Traceability, Availability, Navigability and Customizability.

From the B2B quality characteristics [19] and literature [21], [31], the characteristics of the e-learning systems have been identified as follows:

- Traceability [19]: It is used for tracing the e-learning 
operations such as learning content creation, content transfer and content delivery.

- Availability [19]: It refers to the extent to which the learning content is available for learners whenever the system is required. Availability is of great importance in e-learning applications.

- Navigability [19]: This characteristic refers to the ease of users' quick and efficient access to the content

- Accessibility [21], [31]: The e-learning system is able to provide the access for the remote locations.

TABLE II: MOST COMMON QUALITY CHARACTERISTICS OF THE WeB APPLICATIONS [19]

\begin{tabular}{lc}
\multicolumn{2}{c}{ APPLICATIONS [19] } \\
\hline Quality Factor & Rank \\
\hline Efficiency & 1 \\
Security & 2 \\
Usability & 3 \\
Traceability & 4 \\
Availability & 5 \\
Scalability & 6 \\
Functionality & 7 \\
Customizability & 8 \\
Recoverability & 9 \\
Consistency (Data) & 10 \\
\hline
\end{tabular}

\section{The Quality of the Learning Content and the Used} Pedagogical and Cognitive Approaches

The quality of an e-learning course is enhanced by [2]:

- The learner-centered content: It refers to the e-learning software capability in accordance with the learners' needs, roles and responsibilities. The e-learning software should provide the skills, knowledge and information for its learners.

- The granularity: It refers to the segmentation of the learning content to facilitate assimilation of new knowledge and to allow flexible scheduling of time for learning.
- The engaging content: It is refers to the extent to which the e-learning software is motivating the learning experience. Instructional methods and techniques should be used to develop an engaging content [32].

- The interactivity: It refers to the e-learning software capability for sustaining attention of learner. Frequent learner interaction should be used to promote learning.

- The personalization: It refers to the extent to which the e-learning software is customized to reflect learners' interests and needs;

- Consistency (Data): is the data of the e-learning content consistent?

- Communication and cooperative learning [32], [33] : The ability of the e-learning to provide communication, exchange, collaboration and the development not-only of ICT basic skills, but a full range of social and communication skills;

- Quick distribution of learning contents [31]: It refers to the extent to which the e-learning software provides a more open approach to contents and the quick distribution of learning contents.

\section{The Business Quality Characteristics}

Return on Investment: The indicator of return on investment is of great importance for organizations providing e-learning systems; it could be measured through [21]:

- Reactions at the end of the course,

- Change of learning attitudes,

- Knowledge and skill improvement,

- Change of behavior,

- Results of changes in key business.

Sustainability [22]: It refers to the extent to which the e-learning software is sustainable for the business managers.

Table III lists the most quality characteristics of the e-learning systems.

TABLE III: MOST COMMON QUALITY CHARACTERISTICS OF THE E-LEARNING SYSTEMS

\begin{tabular}{|c|c|c|}
\hline $\begin{array}{l}\text { Quality characteristics of the web } \\
\text { technologies }\end{array}$ & $\begin{array}{l}\text { Quality of the learning content, pedagogical and cognitive } \\
\text { approaches }\end{array}$ & Business quality characteristics \\
\hline \multirow{8}{*}{$\begin{array}{ll}\text { 1. } & \text { Traceability [19] } \\
\text { 2. } & \text { Availability [19] } \\
\text { 3. Navigability [19] } \\
\text { 4. Accessibility [21], [31] }\end{array}$} & 1. The learner-centered content [2] & 1. Return on Investment[21] \\
\hline & 2. The granularity [2] & 2. Sustainability [22] \\
\hline & 3. The engaging content [32] & \\
\hline & 4. The interactivity [2] & \\
\hline & 5. The personalization [2] & \\
\hline & 6. Consistency (Data) [2] & \\
\hline & 7. Communication and cooperative learning [32], [33]; & \\
\hline & 8. Quick distribution of learning contents [31] & \\
\hline
\end{tabular}

Once the quality characteristics of the e-learning systems have been identified, they will be integrated into the quality model of Fig. 3 in the next section.

\section{E. Add the Identified Characteristics to the Quality Model of Fig. 3}

Fig. 4 shows the integration of these characteristics at the second level of the model.
Reliability characteristic: Availability Functionality characteristic:

1) Accessibility

2) The learner-centered content

3) The granularity

4) The engaging content

5) The interactivity

6) The personalization 
7) Communication and cooperative learning

Efficiency characteristic: Quick distribution of learning contents

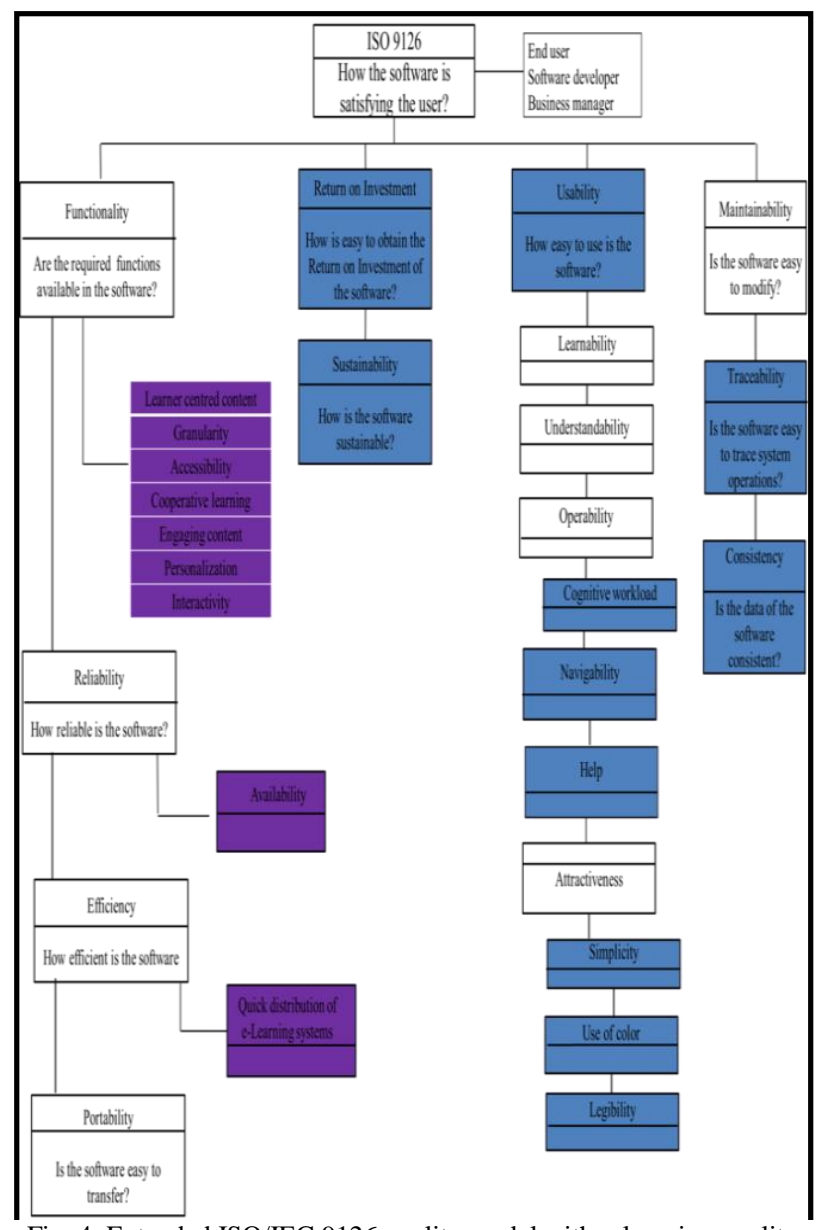

Fig. 4. Extended ISO/IEC 9126 quality model with e-learning quality characteristics.

\section{CONCLUSION}

This work has proposed a model for software product evaluation in e-learning based on the ISO 9126 standard. The immediate contribution of this work is related to the identification of novel quality characteristics for e-learning systems. The future research in this field includes the validation and evaluation of the proposed model in a realistic case of an educational organization or university; and the development of an ISO 9126 based evaluation tool for the e-learning systems.

\section{REFERENCES}

[1] M. Bari and R. Djouab, "The current situation of e-learning," In Preparation, 2014.

[2] FAO Trust Fund Project GCP/GLO/279/GER, "E-learning methodologies," Food and Agriculture Organization of the United Nations, Rome, 2011.

[3] E. R. Bialo and J. S. Kachala, "The effectiveness of technology in schools: A summary of recent research," $S L M Q, 1996$, vol. 25, no. 1.

[4] S. E. Yager and Z. Szabo, "Using an e-book to teach technology: Effects on student performance," presented at the 49th SIGMIS Annual Conference on Computer Personnel Research, 2011.

[5] What Is the History of Online Education? Degrees \& Courses from Top Colleges and Universities, February 12, 2013.

[6] L. B. Baruque, C. B. Baruque, and R. N. Melo, "Towards a framework for corporate e-learning evaluation," in Proc. the Euro American Conference on Telematics and Information Systems, May 14-17, New York: ACM Press, 2007, pp. 1-2.
[7] M. Caramihai and I. Severin, "Elearning tools evaluation based on quality concept distance computing: A case study," World Academy Sci., Eng. Technol., vol. 53, pp. 569-573, 2009.

[8] S. Ozkan and R. Koseler, "Multi-dimensional students' evaluation of e-learning systems in the higher education context: An empirical investigation," Comput. Educ. vol. 53, pp. 1285-1296, 2009.

[9] Y. Yunus and J. Salim, "Framework for the evaluation of e-learning in Malaysian public sector from the pedagogical perspective," in Proc. the International Symposium on Information Technology, Aug. 26-28, IEEE Xplore Press, Kuala Lumpur, 2008, pp. 1-8.

[10] M. Abdellatief, A. B. M. Sultan, M. A. Jabar, and R. Abdullah, "A technique for quality evaluation of e-learning from developers perspective," American Journal of Economics and Business Administration, vol. 3, pp. 157-164, 2011.

[11] U. D. Ehlers, L. Goertz, B. Hildebrandt, and J. M. Pawlowski, "Quality in e-learning use and dissemination of quality approaches in European e-learning," A study by the European Quality Observatory, 2005.

[12] J. A. McCall, Factors in Software Quality, General Electric: National Technical Information Service, 1977.

[13] B. Boehm, J. Brown, H. Kaspar, M. Lipow, G. MacLeod, and M. Merritt, Characteristics of Software Quality, TRW Series of Software Technology, TRW Systems and Energy, Inc. 1973.

[14] D. R. Geoff, "A model for software product quality," Journal of IEEE Transactions on Software Engineering, vol. 21, no. 2, pp. 146-162, 1995.

[15] ISO/IEC 9126, Software Engineering - Product quality, Parts 1-4, 1999-2004.

[16] Quality of Experience (QoE) - A Systematic Literature Survey. (July 2014). [Online]. Available: http://qoe.1t/140/iso-9126-standard/

[17] W. Suryn and D. Girard, "Suryn-abran consolidated quality lifecycle (CQL) model - The applicative evolution," BIS 2005, Poznan, Poland, April 20-22, pp. 126-146.

[18] S. Fahmy, N. Haslinda, W. Roslina, and Z. Fariha, "Evaluating the quality of software in e-book using the ISO 9126 model," International Journal of Control and Automation, vol. 5, no. 2, 2012.

[19] B. Behkamal, M. Kahani, and M. K Akbari, "Customizing ISO 9126 quality model for evaluation of B2B applications," Information and Software Technology, vol. 51, pp. 599-609, 2008.

[20] M. Alkhattabi., D. Neagu, and A. Cullen, "Information quality framework for e-learning systems," Knowledge Management \& e-learning: An International Journal, vol. 2, no. 4, pp. 340-362, 2010.

[21] K. Klasnic, J. L. Lazic, and S. Seljan, "Quality metrics of an integrated e-learning system - Students' perspective, e-learning experiences and future," InTech., ISBN: 978-953-307-092-6, 2010.

[22] L.Yuan and S. Powell. (2013). MOOCs and open education: Implications for higher education. JISC Cetis Centre of Educational Technology and Interoperability Standards. [Online]. Available: http://publications.cetis.ac.uk/wp-content/uploads/2013/03/MOOCs-a nd-Open-Education.pdf

[23] B. B. Chua and L. E. Dyson, "Applying the ISO 9126 model to the evaluation of an e-learning," in Proc. the 21st ASCILITE Conference, 2004, pp. 184-190.

[24] N. Bevan, "Measuring usability as quality of use," Software Quality Journal, vol. 4, pp. 115-150, 1995.

[25] P. P. Kotze et al., "ISO 9126 external systems quality characteristics, sub-characteristics and domain specific criteria for evaluating e-learning systems," presented at SACLA Conference, 2010.

[26] S. Valenti, A. Cucchiarelli, and M. Panti, "Computer based assessment systems evaluation via the ISO9126 quality model," Journal of Information Technology Education, vol. 1, no. 3, pp. 157-175, 2002.

[27] S. B. Vassiliadis and M. Xenos, "On the quality assessment of advanced e-learning services," Interactive Technology and Smart Education, vol. 3, no. 3, 2004.

[28] M. Bari and R. Djouab, "Software quality and e-learning," presented at International Conference on e-Education, Mostar, Bosnia and Herzegovina, September 26-27, 2014

[29] S. Meredith and B. Newton, "Models of e-learning: Technology promise vs. learner needs-literature review," The International Journal of Management Education, pp. 43-56, 2003.

[30] E. L. Meyen, P. Tangen, and C. Lian, "Developing online instruction: Partnership between instructors and technical developers," Journal of Special Education Technology, vol. 14, no. 1, pp. 18-31, 1999.

[31] C. Dondi and M. Moretti, "E-learning quality in European universities: Different approaches for different purposes," UNIQue (European University Quality in eLearning), 2007.

[32] J. Stephenson, Definitions of Indicator of Quality on the Application of ICT to University Teaching, Tarragona, Spain, 2005.

[33] C. Graham, J. Lim, B. Cagiltay, J. Craner, and T. M. Duffy, Seven Principles of Effective Teaching: A Practical Lens for Evaluating Online Courses, Michigan Virtual University, 2001. 


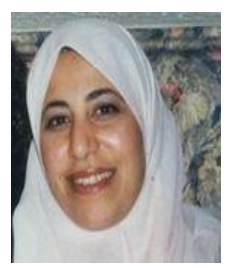

Rachida Djouab is a postdoctoral candidate at University of Quebec at Montreal since 2013. She was born in Algeria in 1967. She first completed her bachelor degree in computer science, followed by a master degree in medical informatics in France. She also completed her $\mathrm{PhD}$ and MA degrees in software engineering at ÉTS and UQÀM (Montreal). Her research interests are in quality engineering of the software product (software product quality engineering) and management of business processes (business process management); design of the engineering processes of the quality requirements of the software product; and software engineering standardization.

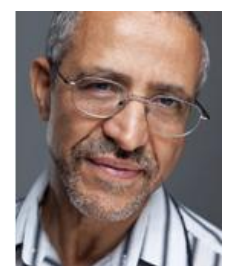

Moncef Bari is a permanent professor at the University of Quebec at Montreal (Canada) since 1998 where he has been the vice-dean for studies of the Faculty of Education for 6 years. He has been an associate researcher at LIP6 Laboratory (University Paris 6, UA 818 CNRS) where he developed a method of analysis and design of active information systems. As a research associate at the Computer Science Research Centre of Montreal, he worked on ROOM ObjecTime for embedded systems.

Moncef first completed his engineer degree in computer science from CERI (Algiers) and a master degree in economics (University of Algiers). He then completed a master and a Ph.D. in computer science from the University Pierre and Marie Curie (France)

Prof. Moncef Bari's main esearch fields are in software engineering and educational technology. 